\title{
Seasonal variability of chlorophyll-a and oceanographic conditions in Sabah waters in relation to Asian monsoon`a remote sensing study
}

\begin{abstract}
A study was conducted to investigate the influence of Asian monsoon on chlorophyll-a (Chla) content in Sabah waters and to identify the related oceanographic conditions that caused phytoplankton blooms at the eastern and western coasts of Sabah, Malaysia. A series of remote sensing measurements including surface $\mathrm{Chl}-\mathrm{a}$, sea surface temperature, sea surface height anomaly, wind speed, wind stress curl, and Ekman pumping were analyzed to study the oceanographic conditions that lead to large-scale nutrients enrichment in the surface layer. The results showed that the Chl-a content increased at the northwest coast from December to April due to strong northeasterly wind and coastal upwelling in Kota Kinabalu water. The southwest coast (Labuan water) maintained high concentrations throughout the year due to the effect of Padas River discharge during the rainy season and the changing direction of Baram River plume during the northeast monsoon (NEM). However, with the continuous supply of nutrients from the upwelling area, the high Chl-a batches were maintained at the offshore water off Labuan for a longer time during NEM. On the other side, the northeast coast illustrated a high Chl-a in Sandakan water during NEM, whereas the northern tip off Kudat did not show a pronounced change throughout the year. The southeast coast (Tawau water) was highly influenced by the direction of the surface water transport between the Sulu and Sulawesi Seas and the prevailing surface currents. The study demonstrates the presence of seasonal phytoplankton blooms in Sabah waters which will aid in forecasting the possible biological response and could further assist in marine resource managements.
\end{abstract}

Keyword: MODIS Aqua; Chlorophyll-a; Upwelling; Sabah waters; Remote sensing; GIS; East Malaysia 